\title{
Characterization of Isolates of Fusarium spp. Obtained from Asparagus in Spain
}

C. Corpas-Hervias, IFAPA "Las Torres-Tomejil", Junta de Andalucía, 41200 Alcalá del Río (Sevilla), Spain; J. M. Melero-Vara and M. L. Molinero-Ruiz, Institute for Sustainable Agriculture, CSIC, Apdo. 4084, 14080 Córdoba, Spain; and C. Zurera-Muñoz and M. J. Basallote-Ureba, IFAPA "Las Torres-Tomejil", Junta de Andalucía, 41200 Alcalá del Río (Sevilla), Spain

\begin{abstract}
Corpas-Hervias, C., Melero-Vara, J. M., Molinero-Ruiz, M. L., Zurera-Muñoz, C., and Basallote-Ureba, M. J. 2006. Characterization of isolates of Fusarium spp. obtained from asparagus in Spain. Plant Dis. 90:1441-1451.

Microbial analysis of asparagus plants (Asparagus officinalis) obtained from four nurseries in Spain in 2002 to 2003 indicated high frequencies of Fusarium proliferatum, F. oxysporum, and F. moniliforme in the rhizomes and storage roots. Out of 201 isolates of Fusarium obtained from nursery crowns and from plants sampled in nine established asparagus fields, the highest frequency of highly pathogenic isolates was observed from samples collected from fields, and included some extremely virulent isolates of $F$. solani. For isolates of low to moderate virulence, the percentage of those significantly $(P=0.01)$ associated with root dry weight loss was larger for F. proliferatum (53.8\%) than for the other Fusarium species (10.3 to 23.1\%). Random amplified polymorphic DNA (RAPD) analysis of 19 isolates of Fusarium spp. grouped all F. proliferatum and $F$. moniliforme isolates together and, in a second cluster, five of the eight isolates of $F$. oxysporum. Asparagus cultivars Verde-Morado and Dariana were the least susceptible of 11 cultivars commonly grown in Spain; isolates of $F$. solani and $F$. moniliforme proved highly virulent; and a significant interaction was observed among pathogen isolates and asparagus cultivars when representative pathogenic isolates of $F$. proliferatum, $F$. oxysporum, $F$. moniliforme, and $F$. solani were tested on those cultivars. Larger reductions in root dry weight were associated with $F$. proliferatum and $F$. solani than with $F$. oxysporum and $F$. moniliforme, and differences in root and stem dry weights among cultivars were significant.
\end{abstract}

Additional keywords: crown and root rot, cultivar susceptibility, fingerprinting

Asparagus officinalis L. is one of the main horticultural crops in Spain, the fourth country in importance of asparagus production, after China, Peru, and the United States (37). An important expansion in acreage of the crop in South Spain has occurred during the past two decades, mainly because fresh asparagus can be exported to other European Union countries early in the season (37). About $75 \%$ of asparagus production in Spain is currently in the south of the country (37).

Premature decline of asparagus crops, and problems associated with the replanting of fields previously cropped to asparagus, have been reported in different areas of the world $(3,7,12,16,22,23,36,40)$. The problem has been attributed to both biotic and abiotic factors, although it is thought to be associated mainly with pathogenic soilborne fungi, especially Fusarium spp.

Corresponding author: J. M. Melero-Vara

E-mail: cs9mevaj@uco.es

Accepted for publication 20 June 2006.

DOI: 10.1094/PD-90-1441

This article is in the public domain and not copyrightable. It may be freely reprinted with customary crediting of the source. The American Phytopathological Society, 2006.
(16). Fusarium wilt of asparagus was first detected in Spain in the late 1970s, and $60 \%$ of fields surveyed in the north of the country were found to be affected by the disease 10 years later (19).

Fusarium oxysporum (Schlecht.) emend. Snyd. \& Hans. f. sp. asparagi Cohen \& Heald and $F$. proliferatum (Mats.) Nirenb. are the most important species of Fusarium pathogens of asparagus (15). F. moniliforme (Sheld.) emend. Snyd. \& Hans. seems to occur less frequently on asparagus than $F$. oxysporum and $F$. proliferatum since the taxonomic separation of the latter from $F$. moniliforme based on the presence of polyphialides and VCG assignment $(14,33)$. $F$. roseum, $F$. solani, $F$. subglutinans, $F$. culmorum, $F$. equiseti, and $F$. redolens are found less frequently in affected asparagus fields than the other Fusarium spp. mentioned above $(1,3,8,11-$ 16,19-21,25,28,36,40). The random amplified polymorphic DNA-polymerase chain reaction (RAPD-PCR) technique has been useful to distinguish species within genera, including Fusarium spp. (43). Genetic studies based on RAPD have not been performed on Fusarium spp. affecting asparagus. However, F. redolens has been differentiated from $F$. oxysporum by restriction fragment length polymorphisms (RFLP) analysis of the rDNA internal tran- scribed spacer (ITS) region and amplified fragment length polymorphisms (AFLP) analyses (1).

The particular Fusarium spp. involved in the asparagus decline complex depend on the geographical area (15), although the species cause similar symptoms. Symptoms include reduced plant size $(13,15)$, wilt of aerial plant parts (7), rots of the roots, rhizomes, and stems $(18,25)$, vascular discoloration of the rhizome and stem bases $(11,12,21,36)$, and brown lesions on root and stem surfaces $(3,11,36)$. The Fusarium species pathogenic to asparagus survive in the soil as chlamydospores (33) or as mycelium in infected plant debris $(15,34)$, and are disseminated with asparagus propagation materials $(4,8,10,11,20$, 23,40 ). However, internal infection of the crowns determines establishment of the pathogen in pathogen-free soil (4). This contrasts with the much lower epidemiological importance of seedborne inoculum, which is confined to the seed surface and, therefore, readily eliminated by seed disinfestation (23).

To prevent Fusarium diseases of asparagus and, hence, to ensure crop profitability, several control measures are deployed, including certification of pathogen-free planting material and planting into pathogen-free fields $(4,9)$. The most successful strategy for controlling Fusarium diseases in many horticultural crops is the development of resistant cultivars (29). This approach has not been widely studied in the asparagus/Fusarium pathosystem because of the difficulty of finding resistance to these pathogens. Lack of host resistance is due, in part, to broad genetic diversity within the pathogen populations and a lack of genetic uniformity of asparagus cultivars $(5,27)$.

One-year-old crowns produced in commercial nurseries are the most common type of material used for field planting $(4,20)$. Therefore, sanitary conditions of nursery crowns are crucial for obtaining sustainable and productive crops. The objectives of this work were to: (i) determine the incidences of different Fusarium species that occur in asparagus crowns from nurseries; (ii) characterize isolates recovered from nursery crowns using morphological, pathogenic, and molecular characters; and (iii) study interactions of the pathogens with asparagus cultivars that possess the most valuable agronomic traits. 


\section{MATERIALS AND METHODS}

Analysis of plant material. Twenty-six commercial lots of 1-year-old asparagus crowns of 13 cultivars that were grown in four nurseries were analyzed in 2002 and 2003 (Table 1). Crowns were provided by nine producers, and were intended for new plantings. Thirty crowns were randomly selected from each lot. In addition, diseased and apparently healthy plants were sampled (two to four plants) from each of nine established asparagus fields in southern Spain that were severely affected by Fusarium wilt in 2002 and 2003. Prior to carrying out isolations from the plant tissues, the severity of symptoms on each asparagus crown was assessed on a scale of 1 to 3 , where $1=1$ to $10 \%, 2=11$ to $50 \%$, and $3=51$ to $100 \%$ of the root system showing symptoms of infection by Fusarium spp.

Different parts of the nursery crowns were assayed for infection by Fusarium spp., including one or more pieces (5 to 10 $\mathrm{mm}$ long) of the rhizome, one piece from each of three storage roots, and one piece from each of three secondary roots. Each plant tissue section was rinsed in tap water for $20 \mathrm{~min}$ and surface-disinfested for $3 \mathrm{~min}$ by immersion in $20 \%$ household bleach ( 50 $\mathrm{g}$ of active chlorine per liter). Segments 2 to $4 \mathrm{~mm}$ long of the tissue were aseptically transferred to petri dishes containing either potato dextrose agar (Difco) acidified with $2.2 \mathrm{ml} /$ liter $85 \%$ lactic acid (PDAa) or water agar amended with $35 \mathrm{mg} /$ liter tetracycline hydrochloride (WAt). Dishes were incubated at $25^{\circ} \mathrm{C}$ for 2 days in darkness, then for 5 to 8 days with a 12-h photoperiod (33). Isolates from symptomless plants were obtained from the rhizosphere and rhizoplane of storage roots according to the method described by Melo et al. (31). Isolates were identified to genus by colony morphology on PDA and by observation of fungal structures microscopically (2).

Pathogenicity tests in vitro. Eighteen sequential experiments were carried out to test 201 isolates of Fusarium spp., 137 from nursery asparagus crowns and 64 from commercial fields that displayed symptoms of Fusarium wilt; one isolate (Fe 1/01) was obtained from an asparagus spear.

Asparagus seeds of cultivar UC- 157 were surface-disinfested by immersion for 2 min in a household bleach solution as described above, then air-dried, transferred to WA $(0.6 \%)$ under sterile conditions, and kept in the dark at $25^{\circ} \mathrm{C}$ for 6 to 7 days. Once roots began to emerge, seedlings were individually transferred under sterile conditions to test tubes containing $20 \mathrm{ml}$ of Hoagland medium (42). Tubes were capped and kept for 2 weeks in a growth chamber set at $25 / 18^{\circ} \mathrm{C}$ (day/night) with fluorescent light providing a 16-h photoperiod, until inoculation. Inoculum of each Fusarium isolate was produced on PDA plates incubated at $25^{\circ} \mathrm{C}$ and a 12-h photoperiod per day for 10 days. Each dish was flooded with sterile distilled water and scraped with a scalpel to loosen the spores. The spore suspension was filtered through four layers of sterile cheesecloth, spore concentration was determined using a hemacytometer, and the suspension was diluted with sterile water to obtain a final concentration of $1 \times 10^{7}$ conidia $/ \mathrm{ml}$. Each plant was inoculated by adding $1 \mathrm{ml}$ of the appropriate conidial suspension to the roots, and inoculated plants were then incubated for 3 weeks. One milliliter of sterile water was added to each control plant. Six plants (replicates) were inoculated per isolate, and each of the 201 isolates was tested. The incidence of plants showing symptoms of infection of the roots or stems was assessed weekly. Severity of the lesions on the root system was assessed similarly on a 1 to 5 scale where $1=1$ to $20 \%, 2=21$ to $40 \%, 3=41$ to $60 \%, 4=61$ to $80 \%$, and $5=81$ to $100 \%$ of the root system affected. Mean \pm standard error of root rot severity ratings over six replicate plantlets inoculated with each

Table 1. Incidence (\%) of Fusarium sp. isolated from 1-year-old asparagus nursery crowns in Spain in 2002 and 2003

\begin{tabular}{lcccc}
\hline & \multicolumn{4}{c}{ Nurseries $^{\mathbf{y}}$} \\
\cline { 2 - 5 } Asparagus cultivar & $\mathbf{1}$ & $\mathbf{2}$ & $\mathbf{3}$ & $\mathbf{4}$ \\
\hline Grolim & 100.0 & 90.0 & - & 100.0 \\
Grande & - & $85.0(66.7-100.0)^{\mathrm{z}}$ & 60.0 & - \\
UC-157 F-1 & - & - & 66.7 & - \\
Verde-Morado & - & 100.0 & - & - \\
Placosesp & - & - & $58.4(50.0,66.7)$ & - \\
$91-21$ & - & - & $70.2(57.1,83.3)$ & - \\
Dariana & - & - & 66.7 & - \\
Ciprés & - & - & $66.6(33.3,100.0)$ & - \\
Steline & - & - & 33.3 & - \\
Plasenesp & - & - & $71.4(42.9,100.0)$ & - \\
Backlim & - & - & - & 62.5 \\
Atlas & - & 100.0 & - & - \\
Jaleo (F1) & - & 100.0 & - & - \\
\hline
\end{tabular}

${ }^{y}$ Numbers under nursery heading indicate the four different asparagus nurseries sampled.

${ }^{\mathrm{z}}$ Numbers in parentheses refer to incidence of Fusarium spp. in two lots when separated by a comma or more lots (when separated by a dash) of nursery crowns of the same asparagus cultivar. Thirty randomly sampled plants of each cultivar-nursery combination were assayed for Fusarium. isolate was determined. Isolates with a severity of 2 or higher were considered pathogenic on asparagus (17). Isolations from lesions in four of the six replicates of each treatment were performed onto PDAa and WAt at the end (3 weeks after inoculation) of each experiment for reisolation of the pathogen.

Monoconidial cultures were obtained from isolates that were pathogenic in vitro and morphologically characterized on PDA, $\mathrm{KCl}$-agar, and asparagus stem-agar $(6,11$, $33,39)$. When typical crown and root rot symptoms were caused by an isolate of $F$. oxysporum inoculated on asparagus, the isolate was considered to be f. sp. asparagi (3).

Pathogenicity tests in pots. Nine pathogenicity experiments were conducted sequentially to evaluate 97 monoconidial isolates demonstrated as pathogenic in the in vitro tests, together with isolate Fe 1/02 obtained from asparagus spears. These isolates were cultured in potato dextrose broth (PDB) on a rotary shaker $(150 \mathrm{rpm})$ at $25^{\circ} \mathrm{C}$ with a 12 -h photoperiod for 10 days. Vermiculite was sterilized twice $\left(121^{\circ} \mathrm{C}\right.$ for 70 min each time) and used as substrate for seeds of the asparagus cultivar UC-157, previously germinated as above described. Plants were then placed in a growth chamber set at a diurnal cycle of $25 / 18^{\circ} \mathrm{C}, 40 / 70 \%$ relative humidity (RH) (day/night), and a 16-h photoperiod. After 2 weeks, inoculations were performed by dipping the roots and stem base of each plant in a suspension of $1 \times 10^{7}$ conidia/ml (10 ml/plant) for $30 \mathrm{~min}$. Control plants were inoculated by immersion in PDB:sterile distilled water (1:1, $\mathrm{vol} / \mathrm{vol})$. Each plant was transplanted into a pot containing $300 \mathrm{ml}$ of sand:peat moss $(1: 1, \mathrm{vol} / \mathrm{vol})$ previously sterilized as described for the vermiculite. After transplanting, $9 \mathrm{ml}$ of a spore suspension of the appropriate Fusarium isolate was added to each pot around the base of the stem of the plant. Plants were incubated for 2 months in a growth chamber under the conditions described above, fertilized weekly with 30 $\mathrm{ml}$ of Hoagland solution per pot, and watered as required.

Ten replicate plants were established for each treatment. Plant stems were evaluated weekly for disease incidence and lesion severity based on a 1 to 5 scale, where $1=$ 1 to $20 \%, 2=21$ to $40 \%, 3=41$ to $60 \%, 4$ $=61$ to $80 \%$, and $5=81$ to $100 \%$ of the stem showing chlorosis, necrosis, or wilt. At the end of each experiment, the plants were removed from the pots, the roots rinsed in tap water, and lesion severity assessed according to the scale described above for the in vitro tests. Mean \pm standard error of root rot severity and stem severity ratings over 10 replicate plants inoculated with each isolate were determined. For each treatment, eight plants were cut above the hypocotyl and dry weight recorded after the plant had dried for 10 days at $50^{\circ} \mathrm{C}$. The remaining two 
plants of each treatment were used for reisolation of the pathogen onto PDAa and WAt. Root dry weights were analyzed by analysis of variance (ANOVA) following a randomized complete block design with eight replicates (pots) with one plant each, and comparisons of means were performed using Tukey's tests $(P=0.01)$. Statistical analyses of data were supported by Statistix 8.0 software (Analytical Software, Tallahassee, FL, USA).

RAPD-PCR. Nineteen monoconidial isolates of Fusarium spp. were selected from isolates characterized in pot experiments according to pathogenicity (seven pathogenic and 12 nonpathogenic) and virulence. Based on the colony morphology and fungal structures, the isolates were identified to species as $F$. oxysporum (isolates 3/8 A, 4/3 B, 9/1 A, 9/3 A, 9/6A, 11/5 AI, CA $1 \mathrm{AS} \mathrm{C}$, and Fe 1/02), F. proliferatum (isolates $2 / 2 \mathrm{~A}, 18 / 1 \mathrm{~A}, 18 / 5 \mathrm{~A}$, and $\mathrm{CO} 4 \mathrm{C} \mathrm{S} \mathrm{A}$ ), $F$. moniliforme (isolates $1 / 20$ $\mathrm{A}, 2 / 18 \mathrm{~B}$, and $2 / 27 \mathrm{~B} 1$ ), and $F$. solani (isolates 16/6 A, CO 4B S B2, and SE $1 \mathrm{~b} \mathrm{~S}$ $\mathrm{C} 1$ ), and isolate $14 / 3 \mathrm{C}$ was noted as a Fusarium sp., because the isolate could not be clearly assigned to any particular species on the basis of morphology. The species of these 19 isolates was not verified until after the various experiments were completed.

Genomic DNA from each isolate was extracted from lyophilized mycelium. To obtain mycelia, each isolate was transferred onto a 9-cm-diameter cellophane disk placed over $25 \mathrm{ml}$ of hardened PDA in a dish. The cultures were grown for 3 to 4 days at $25^{\circ} \mathrm{C}$ with a 12 -h photoperiod. When the colony reached the edge of the dish, the mycelium on the cellophane disk was collected and DNA extracted according to the protocol described by Raeder and Broda (35), with slight modifications. Aliquots of DNA were analyzed on $1 \%$ agarose gels in tris-borate-EDTA buffer (0.1 M tris- $\mathrm{HCl}, 0.1 \mathrm{M}$ boric acid, and 2 mM EDTA at $\mathrm{pH} 8.3$ ) to estimate the quantity and quality of the DNA. For PCR reactions, samples were diluted with MilliQ water (Biotools, Madrid, Spain) to a final concentration of $25 \mathrm{ng} / \mu \mathrm{l}$.

Thirty-eight random 10-mer oligonucleotide primers (Invitrogen Corporation, San Diego, CA, USA) were tested on each of the 19 isolates of Fusarium spp. All reactions were performed in a final volume of $25 \mu \mathrm{l}: 0.4 \mu \mathrm{M}$ primer, $100 \mu \mathrm{M}$ dNTPs, $2.5 \mu \mathrm{l}$ of $10 \times$ reaction buffer $(800 \mathrm{mM}$ tris$\mathrm{HCl}, \mathrm{pH} 8.3$ to 8.4 at $25^{\circ} \mathrm{C}, 0.2 \%$ Tween $20 \mathrm{wt} / \mathrm{vol}), 1 \mathrm{U}$ of Ultratools Polymerase (Biotools), $2.5 \mathrm{mM} \mathrm{MgCl} 2$, and $25 \mathrm{ng}$ of fungal DNA. Amplifications were performed in a T1 Thermocycler (WhatmanBiometra, Goettingen, Germany) programmed for $2 \mathrm{~min} 30 \mathrm{~s}$ denaturation at $94^{\circ} \mathrm{C}$, followed by 45 cycles of $30 \mathrm{~s}$ annealing at $94^{\circ} \mathrm{C}, 1 \mathrm{~min}$ of extension at $36^{\circ} \mathrm{C}$, and denaturation for $2 \mathrm{~min}$ at $72^{\circ} \mathrm{C}$. The last cycle was followed by $5 \mathrm{~min}$ at $72^{\circ} \mathrm{C}$ to produce completely doublestranded DNA fragments. The temperature between annealing and extension was increased at a rate of $5^{\circ} \mathrm{C} / \mathrm{s}$. Amplification products were separated by horizontal electrophoresis on $1 \%$ agarose gels containing $10^{-4} \mathrm{mg} / \mathrm{ml}$ ethidium bromide, and visualized over a UV light source. A 1-kb ladder (Biotools) and a 100- to 2,000-bp ladder (Dominion MBL, Córdoba, Spain) were included in the electrophoresis. Reactions yielding clear polymorphic bands for all the samples were repeated at least once, and negative controls (no template DNA) were included in each assay.

Sixteen primers were selected from the initial screening, because they produced consistent polymorphisms (Table 2). Comparison of the profile for each of the 16 primers was based on the presence (1) or absence $(0)$ of the amplicons that migrated to the same position in the gel. Bands of the same size obtained by the same primer were scored as identical, and only bands that were reproduced in both amplifications with the same primer carried out at different times were evaluated further. A combined binary matrix was generated from the molecular data with the 16 selected RAPD primers. Genetic similarities among isolates were calculated according to Jaccard's similarity coefficient (24) and a dendrogram constructed from the distance matrices using the UPGMA method and the program Fingerprinting II Informatix Software (Bio-Rad Laboratories, Inc., Hercules, CA, USA). The strength of each node of the dendrogram was calculated by generation of 100 bootstrap replications of the data (32).

Reaction of asparagus cultivars to isolates of Fusarium. The reaction of 11 asparagus cultivars of commercial value (Dariana, Plasenesp, Verde-Morado, Steline, Apollo, Jacques Marionnet 2001, Ciprés, UC-157, Placosesp, Grolim, and Grande) to five isolates of Fusarium was

Table 2. Major random amplified polymorphic DNA (RAPD) fragments generated for 19 isolates of Fusarium spp. obtained from asparagus plants in Spain and screened with 16 DNA primers ${ }^{\mathrm{y}}$

\begin{tabular}{llcc}
\hline Primer code & Sequence $\left(\mathbf{5}^{\prime} \mathbf{-} \mathbf{3}^{\prime}\right)$ & $\begin{array}{c}\text { No. of amplicons } \\
\text { scored }^{\mathbf{z}}\end{array}$ & $\begin{array}{c}\text { Size of amplicons } \\
\text { (bp) }\end{array}$ \\
\hline PFE04 & TGGAGAGCAG & 33 & $348-1,667$ \\
PFE05 & TGCCCAGCCT & 28 & $346-2,683$ \\
PFE06 & TGCTGCAGGT & 18 & $471-2,275$ \\
PFE07 & TCTCCGCCCT & 24 & $250-2,277$ \\
PFE08 & CTCTCCGCCA & 19 & $282-2,653$ \\
PFE12 & GGAGGGTGTT & 17 & $351-1,985$ \\
PFE19 & GGTGACTGTG & 24 & $234-2,951$ \\
PFE36 & ACGATCGCGG & 20 & $518-1,905$ \\
PFE34 & GGATGTCGAA & 20 & $300-1,975$ \\
PFE23 & CAGCACCCAC & 24 & $331-2,309$ \\
PFE22 & AATCGGGCTG & 16 & $401-1,843$ \\
PFE21 & TGCCGAGCTG & 30 & $317-2,128$ \\
PFE29 & ACAACGCCTC & 17 & $232-1,967$ \\
PFE31 & GGCGGTTGC & 21 & $387-2,286$ \\
PFE32 & TCTGGCGCAC & 25 & $305-2,234$ \\
PFE35 & GGGCCGTTTA & 22 & $282-1,613$ \\
\hline
\end{tabular}

${ }^{y}$ Primers (Invitrogen) were tested twice on each of the 19 isolates of Fusarium spp.

${ }^{z}$ Only intense and reproducible bands were scored. assessed in each of two repeated experiments conducted in pots, under the controlled conditions above described for the pathogenicity tests in pots. Two isolates of F. proliferatum (2/4 B2 and GR $3 \mathrm{~S}$ B2), one of $F$. oxysporum (Fe 1/02-2), one of $F$. moniliforme $(2 / 27 \mathrm{~B} 2)$, and one of $F$. solani (CA 1B S C) were selected by species and pathogenic criteria from isolates previously tested for pathogenicity. Plants were maintained, inoculated, and incugenicity tests in pots, except the conidial concentration used was $1 \times 10^{6}$ conidia $/ \mathrm{ml}$, the incubation period was 3 months, and three plants were transplanted to each pot.

A third experiment with clonal micropropagated plantlets of the cultivars Dariana, Steline, Ciprés, UC-157, Placosesp, and Grande (provided by C. LópezEncina) was performed using the isolates of Fusarium mentioned in the previous paragraph. The foliage (fern) was removed before inoculation to facilitate handling of the plants. The rest of the methods were similar to those described in the previous paragraph.

These three experiments were carried out on pots containing 1.0 liter of sand:peat moss $(1: 1, \mathrm{vol} / \mathrm{vol})$ with three plants per pot, each pot comprising an experimental unit. Plants were evaluated weekly for severity based on the percentage of the stem showing chlorosis or necrosis. At the end of experiments, disease incidence of plants with root rot severity $\geq 30 \%$, and severity of root rot symptoms (percentage of rotted root), were assessed. For each treatment, dry weights of stem and root were noted as described in pathogenicity tests in pots. Data on incidence and on severity of symptoms, previous angular transformation, and root and stem dry weights were analyzed by ANOVA according to a randomized complete block factorial design with three replicates (pots). Comparisons of means were perbated as described above for the patho- 
formed using Tukey's tests $(P=0.05)$. Data were statistically analyzed using Statistix 8.0 software.

\section{RESULTS}

Analysis of plant material. Ninety-nine percent of the crowns obtained from nurseries showed a reddish-brown discoloration of the storage roots as well as the tissues within the rhizome (including the central vascular cylinder), and necrotic flecks at the position of attachment of the secondary and storage roots. Symptom severity reached a value of 3 in $71 \%$ of the nursery crowns. Although the number of lesions per crown was low, none of the bulked samples examined was free of symptoms.

The incidence (\%) of Fusarium infections in the planting material analyzed ranged from 33 to $100 \%$ depending on the sample, with the lowest incidence of infec- tion observed on the cultivar Steline (Table 1). All the crowns of the cultivars Grolim, Grande, Verde-Morado, Ciprés, Plasenesp, Atlas, and Jaleo were infected by Fusarium spp. in at least one of the bulked samples evaluated (Table 1). Most of the fungal isolates were obtained from storage roots $(44 \%)$ and rhizomes $(40 \%)$, with only $16 \%$ from secondary roots. A reddishbrown discoloration of the root vascular system, hollow main roots, scarce secondary roots, and the symptoms described above were also observed on asparagus crowns sampled from all the fields surveyed. Fusarium was recovered from rhizomes, storage roots, and secondary roots from all symptomatic plants as well as from the rhizosphere $(100 \%)$ and rhizoplane $(44 \%)$ of storage roots from symptomless plants sampled in the fields.

Pathogenicity tests in vitro. The first symptoms observed were brown or red- dish-brown necrotic lesions in the root apex and at the junction of secondary and storage roots. Later, necrotic lesions of variable length developed on storage and secondary roots. The numbers of secondary roots also decreased as compared with noninoculated plants. Mainly after inoculation with isolates of $F$. oxysporum or $F$. solani, watery root rot was observed with $29 \%$ of the isolates of these two species. In addition, $91.5 \%$ of isolates caused necrotic flecks or lesions in the stem bases; which also showed external colonization by mycelium of Fusarium, mainly with isolates of $F$. proliferatum $(50 \%)$ and $F$. moniliforme (100\%). Complete lack of symptoms following inoculation was observed with only three isolates.

A wide range in virulence (mean of 1.0 to 4.5) was observed among the Fusarium isolates tested in vitro, with $>67 \%$ of isolates resulting in root rot severity values $\geq 2$

Table 3. Characteristics of Fusarium spp. isolated from asparagus crowns obtained from nurseries in Spain in 2002 and 2003

\begin{tabular}{|c|c|c|c|c|c|c|}
\hline \multirow[b]{2}{*}{ Cultivar } & \multirow[b]{2}{*}{ Isolate code } & \multirow[b]{2}{*}{ Fusarium species } & \multirow{2}{*}{$\begin{array}{l}\text { Severity on roots } \\
\text { in vitro }^{x}\end{array}$} & \multicolumn{2}{|c|}{ Severity of symptoms in pot trials ${ }^{w}$} & \multirow{2}{*}{$\begin{array}{c}\text { Root dry weight } \\
\operatorname{loss}^{y}(\%)\end{array}$} \\
\hline & & & & Roots & Stem & \\
\hline \multirow[t]{2}{*}{ Grolim } & $1 / 14 \mathrm{~A}$ & F. proliferatum & $2.6 \pm 0.5$ & $2.3 \pm 0.5$ & $2.3 \pm 1.0$ & $54.1 * *$ \\
\hline & $1 / 14 \mathrm{~B}$ & F. culmorum & $2.2 \pm 0.4$ & $1.0 \pm 0.0$ & $1.3 \pm 0.5$ & 19.1 \\
\hline \multirow[t]{9}{*}{ Grande } & $2 / 2 \mathrm{~A}$ & F. proliferatum & $2.3 \pm 0.8$ & $1.4 \pm 0.5$ & $2.5 \pm 0.9$ & $75.0 * *$ \\
\hline & $2 / 4 \mathrm{~B} 1$ & F. proliferatum & $2.5 \pm 0.5$ & $2.9 \pm 1.4$ & $2.6 \pm 1.7$ & $79.9 * *$ \\
\hline & $2 / 4 \mathrm{~B} 2$ & F. proliferatum & $2.5 \pm 0.5$ & $3.8 \pm 1.0$ & $3.5 \pm 1.3$ & $81.8 * *$ \\
\hline & $2 / 14 \mathrm{~B}$ & F. oxysporum & $2.2 \pm 1.2$ & $1.0 \pm 0.0$ & $1.1 \pm 0.4$ & 26.4 \\
\hline & $2 / 15 \mathrm{~B}$ & F. moniliforme & $2.0 \pm 0.6$ & $1.5 \pm 0.8$ & $1.9 \pm 1.0$ & $61.9^{* *}$ \\
\hline & $2 / 18 \mathrm{~B}$ & F. moniliforme & $2.7 \pm 0.5$ & $1.0 \pm 0.0$ & $1.4 \pm 0.5$ & 4.9 \\
\hline & 2/27 B1 & F. moniliforme & $2.3 \pm 0.8$ & $3.5 \pm 0.5$ & $3.6 \pm 0.7$ & $86.0^{* *}$ \\
\hline & 2/27 B2 & F. moniliforme & $2.3 \pm 0.8$ & $3.0 \pm 0.8$ & $2.9 \pm 0.8$ & $47.1 * *$ \\
\hline & $2 / 29 \mathrm{~A}$ & F. moniliforme & $2.2 \pm 1.0$ & $2.4 \pm 0.7$ & $1.6 \pm 0.9$ & $71.1 * *$ \\
\hline \multirow{4}{*}{ UC-157 F-1 } & $3 / 4 \mathrm{~B}$ & F. proliferatum & $3.2 \pm 0.4$ & $3.1 \pm 1.6$ & $3.4 \pm 1.6$ & $90.0 * *$ \\
\hline & $3 / 8 \mathrm{~A}$ & F. oxysporum & $2.5 \pm 0.5$ & $1.0 \pm 0.0$ & $1.0 \pm 0.0$ & 29.7 \\
\hline & $3 / 24 \mathrm{~A}$ & $F$. proliferatum & $3.2 \pm 0.4$ & $2.1 \pm 0.4$ & $2.6 \pm 0.7$ & $83.7^{* *}$ \\
\hline & $3 / 26 \mathrm{~A}$ & F. proliferatum & $2.7 \pm 0.5$ & $\mathrm{NA}^{\mathrm{z}}$ & NA & NA \\
\hline \multirow[t]{6}{*}{ Verde-Morado } & $4 / 2 \mathrm{~B}$ & F. moniliforme & $3.5 \pm 0.5$ & $1.1 \pm 0.4$ & $1.3 \pm 0.5$ & $52.3^{* *}$ \\
\hline & $4 / 3 \mathrm{~A}$ & $F$. proliferatum & $3.0 \pm 0.0$ & $3.0 \pm 1.1$ & $3.1 \pm 1.1$ & $92.8 * *$ \\
\hline & $4 / 3 \mathrm{~B}$ & F. oxysporum & $2.5 \pm 0.5$ & $3.4 \pm 0.9$ & $3.3 \pm 1.0$ & $81.1^{* *}$ \\
\hline & $4 / 5 \mathrm{~B}$ & F. oxysporum & $4.3 \pm 0.5$ & $2.3 \pm 0.5$ & $1.9 \pm 0.8$ & $71.6^{* *}$ \\
\hline & $4 / 6 \mathrm{~B}$ & F. equiseti & $3.0 \pm 0.5$ & $1.4 \pm 0.5$ & $1.4 \pm 0.5$ & 45.1 \\
\hline & $4 / 6 \mathrm{C}$ & F. moniliforme & $2.7 \pm 0.5$ & NA & NA & NA \\
\hline \multirow[t]{2}{*}{ Placosesp } & $5 / 5 \mathrm{~A}$ & F. solani & $4.2 \pm 0.4$ & $2.1 \pm 0.4$ & $2.0 \pm 1.2$ & $63.5^{* *}$ \\
\hline & $5 / 5 \mathrm{~B}$ & Fusarium sp. & $2.7 \pm 0.5$ & NA & NA & NA \\
\hline \multirow{3}{*}{9121} & $7 / 1 \mathrm{~A}$ & F. oxysporum & $2.2 \pm 0.4$ & NA & NA & NA \\
\hline & $7 / 5 \mathrm{~A}$ & F. oxysporum & $2.3 \pm 0.5$ & $1.1 \pm 0.4$ & $1.1 \pm 0.4$ & 8.1 \\
\hline & $7 / 6 \mathrm{~A}$ & F. equiseti & $2.7 \pm 0.5$ & $1.3 \pm 0.5$ & $1.4 \pm 0.5$ & 4.6 \\
\hline \multirow[t]{4}{*}{ Dariana } & $8 / 3 \mathrm{~A}$ & F. proliferatum & $4.3 \pm 0.5$ & $1.0 \pm 0.0$ & $1.0 \pm 0.0$ & 24.7 \\
\hline & $8 / 4 \mathrm{~B}$ & Fusarium sp. & $2.3 \pm 0.5$ & NA & NA & NA \\
\hline & $8 / 5 \mathrm{~A}$ & Fusarium sp. & $2.2 \pm 0.8$ & NA & NA & NA \\
\hline & $8 / 6 \mathrm{~A}$ & F. lateritium & $2.5 \pm 0.5$ & $1.1 \pm 0.4$ & $1.1 \pm 0.4$ & 22.2 \\
\hline \multirow[t]{5}{*}{ Ciprés } & $9 / 1 \mathrm{~A}$ & F. oxysporum & $3.3 \pm 0.5$ & $1.4 \pm 0.5$ & $1.0 \pm 0.0$ & 42.5 \\
\hline & $9 / 2 \mathrm{~A}$ & F. oxysporum & $3.2 \pm 0.8$ & $1.4 \pm 0.5$ & $1.1 \pm 0.4$ & 24.3 \\
\hline & $9 / 3 \mathrm{~A}$ & F. oxysporum & $2.3 \pm 0.5$ & $1.0 \pm 0.0$ & $1.1 \pm 0.4$ & 28.1 \\
\hline & 9/4 A & $F$. proliferatum & $4.0 \pm 0.9$ & $2.1 \pm 0.4$ & $1.5 \pm 0.5$ & 45.5 \\
\hline & $9 / 6 \mathrm{~A}$ & F. oxysporum & $2.7 \pm 0.8$ & $1.6 \pm 0.5$ & $1.3 \pm 0.5$ & 24.8 \\
\hline
\end{tabular}

\footnotetext{
${ }^{\text {w }}$ Spore suspensions $\left(1 \times 10^{7}\right.$ conidia/ml) obtained from colonies of the Fusarium isolates grown on potato dextrose agar (PDA) dishes were used to inoculate roots and stem bases of 2-week-old asparagus plants cv. UC-157 obtained in vermiculite. Severity of symptoms, according to a scale 1 to 5 for the percentage of the stem showing necrosis, was evaluated weekly until 2 months after inoculation. Then, severity of roots was also evaluated. Mean \pm standard error of final scores are average over 10 replicate plants inoculated with each isolate.

${ }^{\mathrm{x}}$ Spore suspensions $\left(1 \times 10^{7}\right.$ conidia/ml) obtained from colonies of the Fusarium isolates grown on PDA dishes were added to the roots of 3-week-old asparagus plantlets cv. UC-157 (1 ml/plantlet) produced in test tubes with Hoagland solution medium. Severity of symptoms, according to a scale 1 to 5 for percentage of root system affected after 3 weeks of incubation. Mean \pm standard error of final scores are average over six replicate plantlets inoculated with each isolate.

${ }^{y}$ At the end of the experiment, eight plants of each treatment were sampled, cut above the hypocotyls, and dry weights recorded after the plant had dried for 10 days at $50^{\circ} \mathrm{C}$. Numbers followed by $* *$ are significantly $(P=0.01)$ different from the corresponding noninoculated control, according to the comparison of means using Tukey's test.

${ }^{\mathrm{z}}$ NA: not assessed in pot trials.
} 
(Tables 3 and 4). Of the Fusarium isolates tested in vitro, $61.3 \%$ of those from nursery crowns and $79.7 \%$ of those from field plants showed mean severity values $\geq 2$. The frequency of isolates with severity $>3$ was also greater for isolates from field plants than for those from nursery crowns. In addition, $69.0 \%$ of the Fusarium isolates obtained from the crowns of symptomless field plants sampled were pathogenic (data not shown).

The frequency distribution of Fusarium isolates obtained from nursery crowns was: $42.7 \%$ F. oxysporum, $28 \% \mathrm{~F}$. proliferatum, $8.5 \%$ F. moniliforme, $3.6 \%$ F. solani, $2.4 \%$ $F$. equiseti, and $1.2 \% \mathrm{~F}$. culmorum and $F$. lateritium. The remaining 10 isolates were Fusarium spp., five of which were included in the taxonomic section Discolor (Table 3) (33). Of the isolates obtained from asparagus plants sampled from fields, $38.2 \%$ were identified as $F$. proliferatum, $29.1 \%$ as $F$. solani, $27.3 \%$ as F. oxysporum, and $1.8 \%$ each as $F$. moniliforme, F. subglutinans, and Fusarium sp. (Table 4).

Pathogenicity tests in pots. The Fusarium monoconidial isolates tested for pathogenicity in pot experiments differed in severity values, and significant differences $(P=0.01)$ were found in losses of root dry weight of inoculated plants (Tables 3 and 4). A highly significant correlation $\left(r^{2}=0.913, P=0.01\right)$ between root rot severity and stem severity ratings was observed. The frequency of isolates with root rot severity ratings $<3$ that showed significantly $(P=0.01)$ larger loss of root dry weights was higher for $F$. proliferatum (53.8\%) than for the other Fusarium spp. studied (10.3 to $23.1 \%$ ) (Tables 3 and 4). However, the general trend was a decrease of percentage of root rot dry weight with increasing severity of root symptoms (Tables 3 and 4). Overall, the frequency of
Fusarium isolates obtained from nursery crowns that were pathogenic to asparagus UC-157 (root rot severity $\geq 2$ ) was $42.9 \%$ (Table 3), in comparison to $68.6 \%$ for isolates collected from diseased plants in affected fields (Table 4). Of the Fusarium isolates obtained from nursery crowns and field plants, the frequencies of isolates resulting in significant $(P=0.01)$ losses in root dry weight in comparison with noninoculated control plants were 52.4 and $77.1 \%$, respectively (Tables 3 and 4). Furthermore, losses in root dry weight due to inoculation with Fusarium isolates obtained from nursery crowns and field plants ranged from 47.1 to $98.2 \%$ and from 51.4 to $99.7 \%$, respectively (Tables 3 and 4).

Forty-eight percent of the Fusarium isolates tested in the pot experiments (77\% of that percentage obtained from nursery crowns) caused root rot severity values $<2$, although all the isolates had previously

Table 3. (continued from preceding page)

\begin{tabular}{|c|c|c|c|c|c|c|}
\hline \multirow[b]{2}{*}{ Cultivar } & \multirow[b]{2}{*}{ Isolate code } & \multirow[b]{2}{*}{ Fusarium species } & \multirow{2}{*}{$\begin{array}{l}\text { Severity on roots } \\
\text { in vitro }\end{array}$} & \multicolumn{2}{|c|}{ Severity of symptoms in pot trialsw } & \multirow{2}{*}{$\begin{array}{c}\text { Root dry weight } \\
\operatorname{loss}^{y}(\%)\end{array}$} \\
\hline & & & & Roots & Stem & \\
\hline \multirow[t]{2}{*}{ Steline } & $11 / 3$ & Fusarium sp. & $2.7 \pm 0.5$ & NA & NA & NA \\
\hline & 11/5 AI & F. oxysporum & $2.5 \pm 0.5$ & $1.8 \pm 0.5$ & $1.1 \pm 0.4$ & 35.3 \\
\hline \multirow[t]{2}{*}{ Plasenesp } & $12 / 1 \mathrm{~A}$ & Fusarium sp. & $2.0 \pm 0.6$ & $1.1 \pm 0.4$ & $1.0 \pm 0.0$ & 28.0 \\
\hline & $12 / 6 \mathrm{~A}$ & F. oxysporum & $2.7 \pm 0.5$ & $1.0 \pm 0.0$ & $1.7 \pm 0.8$ & 4.7 \\
\hline \multirow[t]{4}{*}{ Backlim } & $13 / 3 \mathrm{~A}$ & F. oxysporum & $3.7 \pm 0.5$ & $1.0 \pm 0.0$ & $1.8 \pm 0.4$ & 21.6 \\
\hline & 13/4 B1 & F. proliferatum & $3.7 \pm 0.5$ & $1.0 \pm 0.0$ & $1.2 \pm 0.4$ & 38.7 \\
\hline & 13/4 B2 & F. oxysporum & $2.2 \pm 0.4$ & NA & NA & NA \\
\hline & $13 / 29 \mathrm{~B}$ & F. proliferatum & $3.3 \pm 1.0$ & $1.3 \pm 0.5$ & $1.5 \pm 0.8$ & 46.0 \\
\hline \multirow[t]{6}{*}{ Grande $(\mathrm{F} 1)$} & $14 / 2 \mathrm{~A}$ & F. oxysporum & $2.0 \pm 0.0$ & NA & NA & NA \\
\hline & $14 / 2 \mathrm{~B}$ & F. oxysporum & $3.2 \pm 1.2$ & NA & NA & NA \\
\hline & $14 / 3 \mathrm{~A}$ & Fusarium sp. & $3.5 \pm 0.8$ & NA & NA & NA \\
\hline & $14 / 3 \mathrm{~B}$ & Fusarium sp. & $3.2 \pm 0.4$ & NA & NA & NA \\
\hline & $14 / 3 \mathrm{C}$ & Fusarium sp. & $3.0 \pm 0.6$ & $1.0 \pm 0.0$ & $1.0 \pm 0.0$ & 25.0 \\
\hline & $14 / 4$ B & F. oxysporum & $2.0 \pm 0.6$ & NA & NA & NA \\
\hline \multirow[t]{4}{*}{ Atlas } & $15 / 1 \mathrm{~A}$ & F. oxysporum & $3.2 \pm 1.0$ & $2.7 \pm 1.4$ & $3.0 \pm 1.1$ & $84.6^{* *}$ \\
\hline & 15/1 B & F. oxysporum & $2.7 \pm 0.5$ & NA & NA & NA \\
\hline & $15 / 4 \mathrm{C}$ & F. oxysporum & $2.8 \pm 1.0$ & $1.0 \pm 0.0$ & $1.5 \pm 0.5$ & 25.3 \\
\hline & $15 / 5 \mathrm{~B}$ & F. oxysporum & $2.2 \pm 0.8$ & NA & NA & NA \\
\hline Ciprés & $16 / 6 \mathrm{~A}$ & F. solani & $3.0 \pm 0.0$ & $1.0 \pm 0.0$ & $2.2 \pm 1.0$ & 9.3 \\
\hline \multirow{3}{*}{ Grande } & $17 / 4 \mathrm{~A}$ & F. oxysporum & $3.0 \pm 0.9$ & $2.8 \pm 1.8$ & $3.0 \pm 1.7$ & $65.6^{* *}$ \\
\hline & $17 / 4 \mathrm{~B}$ & F. oxysporum & $2.2 \pm 0.8$ & NA & NA & NA \\
\hline & $17 / 5 \mathrm{~B}$ & F. oxysporum & $3.7 \pm 1.0$ & $2.5 \pm 1.0$ & $2.7 \pm 0.8$ & $81.5^{* *}$ \\
\hline \multirow[t]{6}{*}{ Verde-Morado } & $18 / 1 \mathrm{~A}$ & F. proliferatum & $3.5 \pm 0.5$ & $2.9 \pm 1.0$ & $2.6 \pm 1.1$ & $86.6 * *$ \\
\hline & $18 / 2 \mathrm{~A}$ & F. proliferatum & $2.5 \pm 0.8$ & $1.8 \pm 1.2$ & $2.4 \pm 1.4$ & $64.8 * *$ \\
\hline & 18/4 B1 & F. proliferatum & $2.8 \pm 0.8$ & $1.8 \pm 0.6$ & $1.9 \pm 1.1$ & $70.7 * *$ \\
\hline & 18/4 B2 & F. proliferatum & $2.8 \pm 0.8$ & NA & NA & NA \\
\hline & $18 / 5 \mathrm{~A}$ & F. proliferatum & $2.8 \pm 0.8$ & $2.0 \pm 0.5$ & $2.4 \pm 0.5$ & $68.0 * *$ \\
\hline & $18 / 5 \mathrm{~B}$ & F. proliferatum & $3.2 \pm 0.8$ & $1.1 \pm 0.3$ & $2.2 \pm 0.9$ & $54.2 * *$ \\
\hline \multirow[t]{10}{*}{ Jaleo } & $19 / 1 \mathrm{~A}$ & F. proliferatum & $3.2 \pm 0.8$ & $4.1 \pm 1.3$ & $4.5 \pm 1.1$ & $98.2 * *$ \\
\hline & 19/1 B & F. oxysporum & $2.0 \pm 0.6$ & $3.6 \pm 1.6$ & $3.9 \pm 1.4$ & $94.3 * *$ \\
\hline & 19/1 C1 & F. oxysporum & $3.5 \pm 1.4$ & NA & NA & NA \\
\hline & 19/1 C2 & F. proliferatum & $3.0 \pm 0.6$ & $1.4 \pm 1.3$ & $2.4 \pm 1.3$ & 22.0 \\
\hline & $19 / 2 \mathrm{~B}$ & F. oxysporum & $3.0 \pm 1.4$ & $3.2 \pm 1.8$ & $3.4 \pm 1.3$ & $86.6^{* *}$ \\
\hline & $19 / 2 \mathrm{C}$ & F. proliferatum & $3.0 \pm 1.1$ & $2.3 \pm 1.3$ & $2.8 \pm 1.3$ & $88.1 * *$ \\
\hline & $19 / 3 \mathrm{~B}$ & F. proliferatum & $2.7 \pm 1.2$ & $3.4 \pm 1.3$ & $3.9 \pm 1.0$ & $95.3^{* *}$ \\
\hline & $19 / 4 \mathrm{C}$ & Fusarium sp. & $3.5 \pm 1.0$ & NA & NA & NA \\
\hline & $19 / 5 \mathrm{C}$ & F. oxysporum & $3.7 \pm 1.2$ & $1.0 \pm 0.0$ & $3.0 \pm 0.8$ & $61.8^{* *}$ \\
\hline & $19 / 6 \mathrm{~A}$ & F. proliferatum & $3.0 \pm 1.5$ & $1.6 \pm 0.7$ & $3.3 \pm 0.9$ & $84.9 * *$ \\
\hline \multirow[t]{2}{*}{ Placosesp } & $23 / 1 \mathrm{~A}$ & F. oxysporum & $2.2 \pm 0.8$ & $1.5 \pm 0.5$ & $1.1 \pm 0.3$ & 0.3 \\
\hline & $23 / 3 \mathrm{~A}$ & F. oxysporum & $2.3 \pm 0.8$ & $5.0 \pm 0.0$ & $5.0 \pm 0.0$ & $98.2 * *$ \\
\hline \multirow[t]{4}{*}{9121} & $24 / 2$ B & F. oxysporum & $2.2 \pm 0.8$ & $2.3 \pm 0.7$ & $2.1 \pm 0.7$ & 1.5 \\
\hline & $24 / 4$ B & Fusarium sp. & $2.3 \pm 0.8$ & $4.3 \pm 0.8$ & $4.0 \pm 1.2$ & $91.9 * *$ \\
\hline & $24 / 6 \mathrm{~A}$ & F. oxysporum & $2.8 \pm 0.8$ & $2.2 \pm 0.9$ & $1.9 \pm 0.7$ & $57.4 * *$ \\
\hline & $24 / 6$ B & F. oxysporum & $2.3 \pm 0.8$ & $1.0 \pm 0.0$ & $1.2 \pm 0.4$ & 8.0 \\
\hline Grolim & $25 / 5 \mathrm{~A}$ & F. oxysporum & $3.7 \pm 0.5$ & $1.0 \pm 0.0$ & $1.9 \pm 0.6$ & +23.5 \\
\hline \multirow[t]{2}{*}{ Plasenesp } & $26 / 4 \mathrm{~A}$ & F. solani & $2.5 \pm 0.8$ & $1.0 \pm 0.0$ & $1.2 \pm 0.6$ & 18.7 \\
\hline & $26 / 6 \mathrm{~B}$ & F. oxysporum & $2.5 \pm 0.5$ & $1.0 \pm 0.0$ & $1.5 \pm 0.5$ & +2.4 \\
\hline
\end{tabular}


been characterized as pathogenic in the in vitro tests. Furthermore, $75 \%$ of these isolates did not cause a significant decrease in root dry weight compared with noninoculated control plants. Highly virulent isolates ( $>3$ in root rot and stem severity scales) belonged to $F$. oxysporum, $F$. proliferatum, or $F$. solani, and killed inocu- lated plants by the end of the experiment (Tables 3 and 4).

RAPD-PCR analysis. A total of 358 reproducible polymorphic bands were

Table 4. Morphological and pathogenic characterization of isolates of Fusarium spp. obtained from diseased and symptomless ${ }^{\mathrm{v}}$ asparagus plants in commercial asparagus fields in Spain in 2002 and 2003

\begin{tabular}{|c|c|c|c|c|c|}
\hline \multirow[b]{2}{*}{ Isolate code } & \multirow[b]{2}{*}{ Fusarium species } & \multirow{2}{*}{$\begin{array}{c}\text { Severity on roots } \\
\text { in vitro }^{x}\end{array}$} & \multicolumn{2}{|c|}{ Severity of symptoms in pot trials ${ }^{w}$} & \multirow{2}{*}{$\begin{array}{c}\text { Root dry weight } \\
\operatorname{loss}^{\mathrm{y}}(\%)\end{array}$} \\
\hline & & & Roots & Stem & \\
\hline $\mathrm{Fe} 1 / 02-1$ & F. oxysporum & $1.5 \pm 0.5$ & $4.1 \pm 1.4$ & $4.3 \pm 1.2$ & $92.5 * *$ \\
\hline $\mathrm{Fe} 1 / 02-2$ & F. oxysporum & $1.5 \pm 0.5$ & $4.4 \pm 1.2$ & $4.3 \pm 1.4$ & $90.6 * *$ \\
\hline CA 1 A S A & $F$. proliferatum & $3.5 \pm 0.8$ & $\mathrm{NA}^{\mathrm{z}}$ & NA & NA \\
\hline CA 1 A S B & F. proliferatum & $3.8 \pm 1.6$ & $2.6 \pm 1.0$ & $3.0 \pm 1.1$ & $73.1 * *$ \\
\hline CA 1 A S C & F. oxysporum & $4.0 \pm 0.6$ & $1.0 \pm 0.0$ & $1.1 \pm 0.4$ & 10.6 \\
\hline CA $1 \mathrm{~A} \mathrm{AS} 1^{\mathrm{v}}$ & F. solani & $2.9 \pm 0.5$ & NA & NA & NA \\
\hline CA $1 \mathrm{~B}$ S C $1-1$ & F. solani & $4.2 \pm 0.2$ & $4.9 \pm 0.4$ & $4.5 \pm 0.8$ & $99.5 * *$ \\
\hline CA 1 B S C $1-2$ & F. solani & $4.2 \pm 0.2$ & $5.0 \pm 0.0$ & $4.3 \pm 0.7$ & $98.6 * *$ \\
\hline CA 1 B S C 2 & F. solani & $4.0 \pm 0.9$ & $2.2 \pm 0.6$ & $2.8 \pm 0.8$ & $57.2 * *$ \\
\hline CA 1B S B & F. proliferatum & $3.3 \pm 0.8$ & NA & NA & NA \\
\hline $\mathrm{CA} 1 \mathrm{~B} \mathrm{AS}$ & F. subglutinans & $3.4 \pm 1.1$ & NA & NA & NA \\
\hline CO $3 \mathrm{~S} \mathrm{C}$ & F. moniliforme & $3.8 \pm 1.0$ & $1.6 \pm 0.5$ & $1.1 \pm 0.4$ & $53.0 * *$ \\
\hline $\operatorname{CO} 3 \mathrm{~S} \mathrm{Y}$ & F. proliferatum & $3.2 \pm 0.8$ & $2.8 \pm 1.0$ & $3.6 \pm 1.3$ & $74.5^{* *}$ \\
\hline $\mathrm{CO} 3 \mathrm{AS} 2$ & F. proliferatum & $2.1 \pm 0.7$ & NA & NA & NA \\
\hline $\mathrm{CO} 4 \mathrm{~A} \mathrm{~S} \mathrm{C}$ & F. solani & $3.5 \pm 0.6$ & $1.0 \pm 0.0$ & $1.0 \pm 1.0$ & 26.8 \\
\hline $\mathrm{CO} 4 \mathrm{~B} \mathrm{~S} \mathrm{~A}$ & F. solani & $3.6 \pm 0.7$ & $1.0 \pm 0.0$ & $1.1 \pm 0.4$ & 24.9 \\
\hline CO 4B S B1 & F. proliferatum & $3.0 \pm 0.9$ & $2.8 \pm 0.5$ & $3.1 \pm 0.6$ & $85.2 * *$ \\
\hline CO 4B S B2 & F. solani & $3.7 \pm 0.5$ & $1.3 \pm 0.5$ & $1.3 \pm 0.5$ & $61.3 * *$ \\
\hline $\mathrm{CO} 4 \mathrm{~B} \mathrm{~S} \mathrm{~B} 3$ & F. proliferatum & $3.2 \pm 0.8$ & $2.0 \pm 0.8$ & $2.4 \pm 0.7$ & $75.2 * *$ \\
\hline $\mathrm{CO} 4 \mathrm{C} \mathrm{S} \mathrm{A}$ & F. proliferatum & $3.8 \pm 0.4$ & $4.4 \pm 0.7$ & $4.3 \pm 0.9$ & $98.8 * *$ \\
\hline $\mathrm{CO} 4 \mathrm{C} \mathrm{S} \mathrm{B}$ & F. proliferatum & $3.3 \pm 0.5$ & $5.0 \pm 0.0$ & $5.0 \pm 0.0$ & $99.7 * *$ \\
\hline GR $1 \mathrm{~S}$ A1 & F. proliferatum & $3.0 \pm 1.3$ & $1.1 \pm 0.3$ & $1.0 \pm 0.0$ & 19.0 \\
\hline GR $1 \mathrm{~S}$ A2 & F. proliferatum & $2.2 \pm 0.4$ & NA & NA & NA \\
\hline GR $1 \mathrm{~S} B$ & F. oxysporum & $3.8 \pm 0.4$ & $1.0 \pm 0.0$ & $1.1 \pm 0.4$ & 26.9 \\
\hline GR $1 \mathrm{~S} \mathrm{C} 1$ & F. oxysporum & $2.8 \pm 0.8$ & $1.8 \pm 0.4$ & $1.7 \pm 0.5$ & 33.1 \\
\hline GR $1 \mathrm{~S} \mathrm{C} 2$ & F. proliferatum & $2.5 \pm 0.5$ & $2.7 \pm 0.5$ & $3.4 \pm 0.7$ & $70.9 * *$ \\
\hline GR 1 AS $35^{\mathrm{v}}$ & F. oxysporum & $1,9 \pm 0.5$ & NA & NA & NA \\
\hline GR $2 \mathrm{~S} \mathrm{C}$ & F. oxysporum & $2.8 \pm 0.4$ & $5.0 \pm 0.0$ & $5.0 \pm 0.0$ & $99.4 * *$ \\
\hline GR 2 S B 1 & Fusarium sp. & $2.0 \pm 1.0$ & NA & NA & NA \\
\hline GR $2 \mathrm{~S}$ B2 & F. proliferatum & $2.3 \pm 0.5$ & $2.2 \pm 0.4$ & $2.8 \pm 0.9$ & $51.4 * *$ \\
\hline GR $3 \mathrm{~S}$ A & F. proliferatum & $2.2 \pm 0.8$ & NA & NA & NA \\
\hline GR 3 S B1 & F. proliferatum & $4.3 \pm 0.8$ & $2.1 \pm 0.4$ & $2.0 \pm 0.9$ & $64.4 * *$ \\
\hline GR $3 \mathrm{~S}$ B2 & F. proliferatum & $3.0 \pm 0.9$ & $2.5 \pm 0.8$ & $3.1 \pm 1.0$ & $65.9 * *$ \\
\hline GR 3 AS $10^{v}$ & F. proliferatum & $2.3 \pm 0.8$ & NA & NA & NA \\
\hline GR 3 AS $11^{\mathrm{v}}$ & F. proliferatum & $3.2 \pm 0.9$ & NA & NA & NA \\
\hline GR 4 S A1 & F. solani & $4.0 \pm 0.0$ & $1.0 \pm 0.0$ & $1.0 \pm 0.0$ & 28.9 \\
\hline GR 4 S A2 & F. oxysporum & $4.5 \pm 0.8$ & $2.5 \pm 1.7$ & $2.3 \pm 1.6$ & $76.9 * *$ \\
\hline GR 4 S B1 & F. oxysporum & $3.2 \pm 1.0$ & $2.7 \pm 0.9$ & $2.4 \pm 1.3$ & $68.8 * *$ \\
\hline GR 4 S B2 & F. oxysporum & $4.0 \pm 1.3$ & $4.2 \pm 1.5$ & $4.4 \pm 1.3$ & $89.6 * *$ \\
\hline GR 4 S C1 & F. oxysporum & $4.3 \pm 0.8$ & $3.8 \pm 1.0$ & $3.5 \pm 1.4$ & $91.9 * *$ \\
\hline GR 4 S C2 & F. proliferatum & $2.5 \pm 1.0$ & $2.6 \pm 1.5$ & $3.1 \pm 1.4$ & $66.9 * *$ \\
\hline GR 4 AS $1^{\mathrm{v}}$ & F. proliferatum & $3.5 \pm 0.8$ & NA & NA & NA \\
\hline SE $1 \mathrm{~S} \mathrm{~A}$ & F. proliferatum & $2.7 \pm 0.5$ & NA & NA & NA \\
\hline SE $1 \mathrm{~S} \mathrm{C} 1$ & F. solani & $3.3 \pm 0.8$ & $2.7 \pm 1.5$ & $2.5 \pm 1.6$ & $64.8 * *$ \\
\hline SE $1 \mathrm{~S} \mathrm{C} 2$ & F. oxysporum & $2.8 \pm 0.8$ & NA & NA & NA \\
\hline SE $1 \mathrm{~S} \mathrm{C} 3$ & F. oxysporum & $3.0 \pm 0.6$ & NA & NA & NA \\
\hline SE $1 b$ S B 1 & F. oxysporum & $3.7 \pm 1.2$ & $2.6 \pm 1.7$ & $3.0 \pm 1.3$ & $73.9 * *$ \\
\hline SE 1b S B2 & F. solani & $2.5 \pm 0.5$ & NA & NA & NA \\
\hline SE $1 b$ S C1 & F. solani & $4.0 \pm 0.0$ & $1.3 \pm 0.5$ & $1.0 \pm 0.0$ & 24.3 \\
\hline SE $1 b$ S C 2 & F. solani & $3.3 \pm 1.0$ & $1.8 \pm 1.3$ & $2.0 \pm 1.3$ & $57.0 * *$ \\
\hline SE 2 S B & F. solani & $2.2 \pm 0.8$ & NA & NA & NA \\
\hline SE $2 \mathrm{~S} \mathrm{C} 1$ & F. solani & $2.8 \pm 1.2$ & NA & NA & NA \\
\hline SE 2 S C 2 & F. solani & $3.5 \pm 1.0$ & $4.0 \pm 1.2$ & $3.6 \pm 1.6$ & $92.8 * *$ \\
\hline SE 2 AS $1^{\mathrm{v}}$ & F. oxysporum & $2.9 \pm 1.0$ & NA & NA & NA \\
\hline SE 2 AS $3^{v}$ & F. solani & $3.6 \pm 0.6$ & NA & NA & NA \\
\hline
\end{tabular}

${ }^{\mathrm{v}}$ Isolates from symptomless plants sampled from fields in which other plants showed symptoms of Fusarium wilt.

${ }^{\mathrm{w}}$ Spore suspensions $\left(1 \times 10^{7}\right.$ conidia/ml) obtained from colonies of the Fusarium isolates grown on potato dextrose agar (PDA) dishes were used to inoculate roots and stem bases of 2-week-old asparagus plants cv. UC-157 obtained in vermiculite. Severity of symptoms, according to a scale 1 to 5 for percentage of stem showing necrosis, was evaluated weekly until 2 months after inoculation. Then, severity of roots was also evaluated. Mean \pm standard error of final scores are average over 10 replicate plants inoculated with each isolate.

${ }^{\mathrm{x}}$ Spore suspensions $\left(1 \times 10^{7}\right.$ conidia/ml) obtained from colonies of the Fusarium isolates grown on PDA dishes were added to roots of 3-week-old asparagus plantlets cv. UC-157 (1 ml/plantlet) produced in test tubes with Hoagland solution medium. Severity of symptoms is according to a scale 1 to 5 for percentage of root system affected after 3 weeks incubation. Mean \pm standard error of final scores are the average over six replicate plantlets inoculated with each isolate.

${ }^{y}$ At the end of the experiment, eight plants of each treatment were sampled, cut above the hypocotyls, and dry weights recorded after the plant had dried for 10 days at $50^{\circ} \mathrm{C}$. Numbers followed by $* *$ are significantly $(P=0.01)$ different from the corresponding noninoculated control, according to the comparison of means using Tukey's test.

${ }^{\mathrm{z}} \mathrm{NA}$ : not assessed in pot trials. 
amplified from 19 Fusarium isolates using 16 random primers. The size of the DNA fragments ranged from 232 to $2,951 \mathrm{bp}$, and the number of markers generated by each primer ranged from 16 for primer PFE04 to 33 for primer PFE22 (Table 2). The amplification pattern observed for the 19 Fusarium isolates using primer PFE12 is shown in Figure 1. The dendrogram resulting from the UPGMA analysis of the RAPD data distinguished two robust clusters among the 19 Fusarium isolates (Fig. 2). Cluster I grouped seven isolates identified as $F$. moniliforme or $F$. proliferatum, which shared about $24 \%$ similarity. Five of eight $F$. oxysporum isolates shared $19 \%$ similarity and were grouped in cluster II. The three remaining isolates of $F$. oxysporum grouped close to cluster II (Fig. 2). Neither of $F$. solani isolates $\mathrm{CO} 4 \mathrm{~B} \mathrm{~S}$ B2 and SE 1b S C1 clustered well with either group (Fig. 2). The most divergent amplification profiles were obtained upon amplification of DNA of a third isolate of F. solani (16/6 A) (Fig. 2). For the F. oxysporum isolates $4 / 3 \mathrm{~B}$ and $\mathrm{Fe} 1 / 02-1$, an additional band of 658 bp was observed (lanes four and five in Figure 1). The isolates $4 / 3 \mathrm{~B}$ and $\mathrm{Fe} 1 / 02-1$ proved to be the only pathogenic $F$. oxysporum isolates included in the RAPD analysis (Fig. 2). For the three $F$. moniliforme isolates, RAPD amplifications with primers PFE05 and PFE23 produced bands of 1,514 and $1,402 \mathrm{bp}$, respectively (data not shown). After the amplification with primer PFE12, isolate $2 / 18 \mathrm{~B}$ of $F$. moniliforme had a banding pattern very similar to those of the four isolates of $F$. proliferatum (Fig. 1).

Reaction of asparagus cultivars to isolates of Fusarium. Symptoms were first observed in scattered plants 1 week after inoculation, and consisted of chlorosis of more than $30 \%$ of the aerial plant parts, followed by apical necrosis. These early symptoms occurred on cultivars Dariana, Plasenesp, Verde-Morado, Steline, Apollo, Ciprés, Placosesp, and Grande inoculated with $F$. solani, whereas the other Fusarium spp. evaluated affected only to two to four of the asparagus cultivars assayed.

Based on ANOVAs (30), no significant differences were found between the two experiments with asparagus produced from seeds; therefore data were pooled. For these experiments, a significantly $(P=$ $0.05)$ higher incidence of root rot severity ratings $\geq 30 \%$ was observed on plants inoculated with $F$. solani and $F$. moniliforme (except for cultivar Dariana inoculated with the latter) compared with the other isolates tested and with the control plants (Fig. 3). In contrast, isolate GR $3 \mathrm{~S} \mathrm{~B} 2$ of $F$. proliferatum caused the lowest incidence of root rot ratings $\geq 30 \%$, except for cultivars Apollo, Grolim, and Grande (Fig. 3). Disease incidence was $100 \%$ when the cultivar Grande was inoculated with isolates of either F. solani or F. moniliforme, and when UC-157 was inoculated with $F$. solani (Fig. 3). No disease was observed after inoculation of Steline with the two isolates of $F$. proliferatum, Plasenesp with F. oxysporum, and Placosesp and UC-157 with $F$. proliferatum GR 3 S B2 (Fig. 3). Cultivars Plasenesp, Steline, and Dariana had the lowest overall frequency of symptomatic plants, ranging from 20.8 to $25.0 \%$, regardless of isolate, whereas Grande was the cultivar with the highest

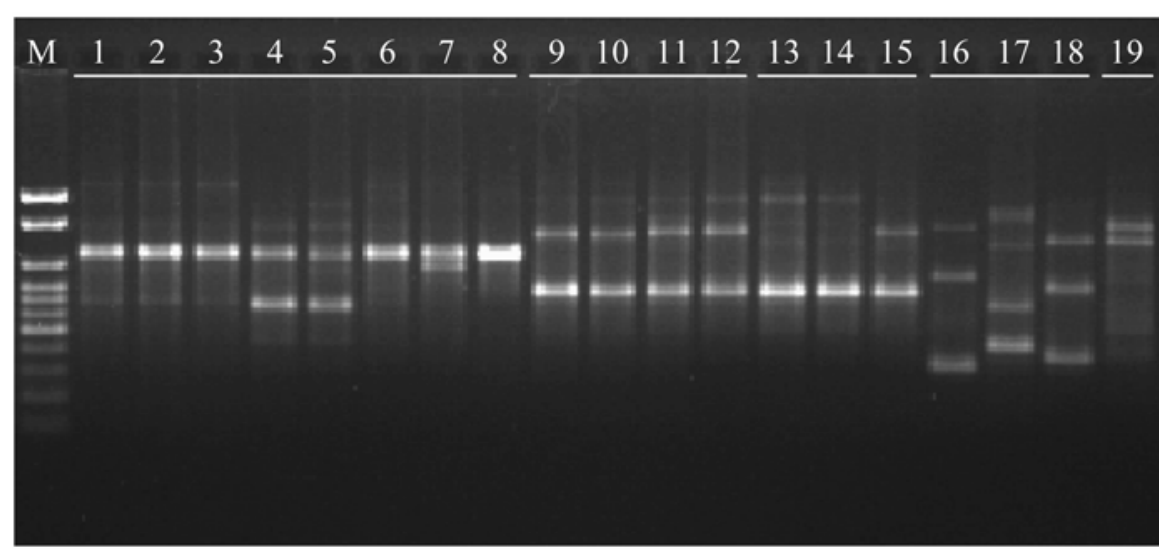

Fig. 1. Random amplified DNA polymorphisms of isolates of Fusarium spp. obtained from asparagus plants, generated using the primer PFE12. Lanes 1 to 8: F. oxysporum; lanes 9 to 12: F. proliferatum; lanes 13 to 15: F. moniliforme; lanes 16 to 18: F. solani; lane 19: Fusarium sp.; M: 100- to 2,000-bp

DNA ladder.

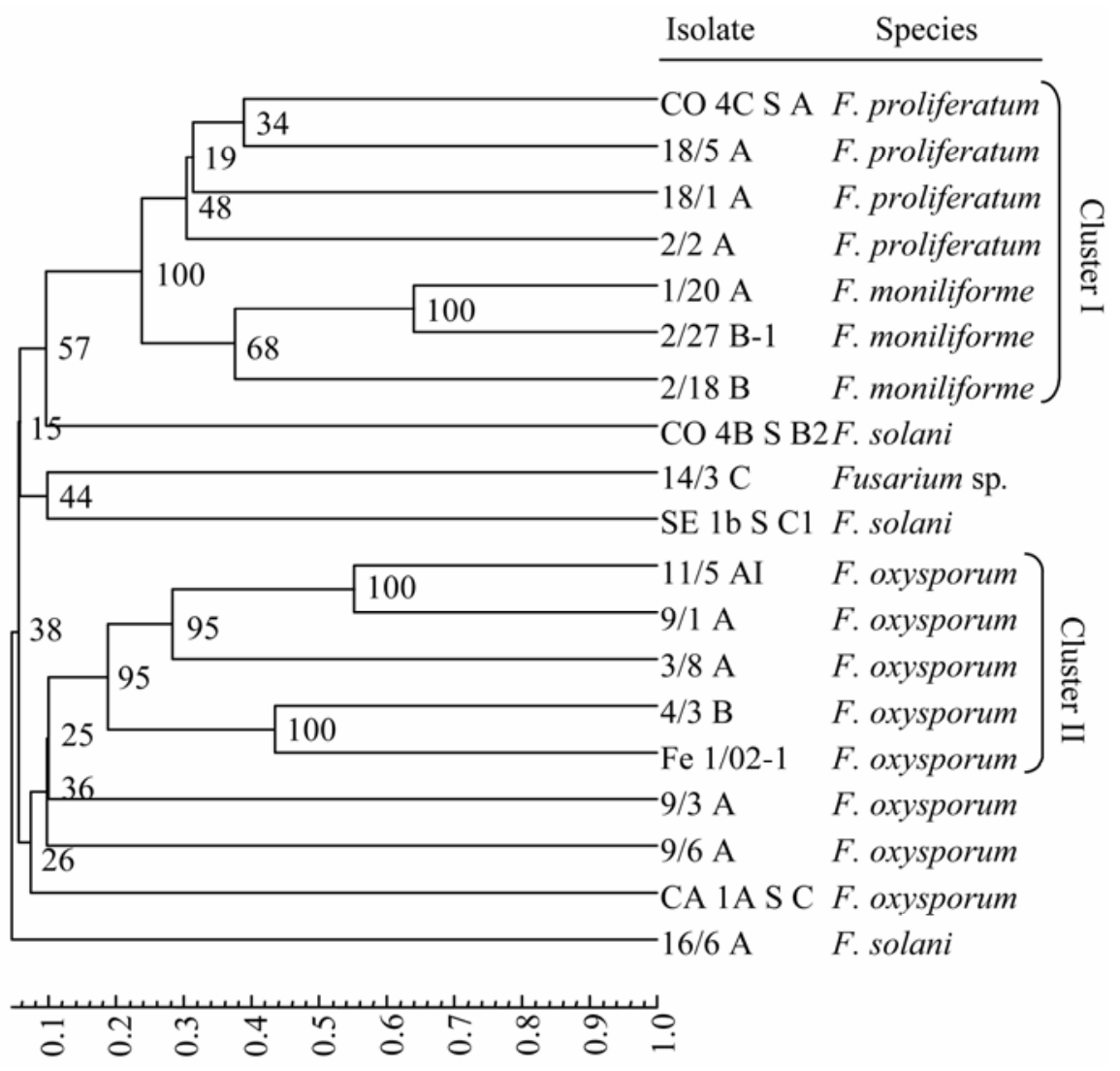

Fig. 2. Dendrogram derived from random amplified polymorphic DNA (RAPD) analysis of DNA from 19 isolates of Fusarium spp. obtained from asparagus plants, and generated using 16 10-mer primers (see Table 2) and the unweighted paired group method with arithmetic averages (UPGMA). Scale represents percent similarity using Jaccard's similarity coefficient (24). Bootstrap support percentages for 100 replicates are indicated at the nodes. overall incidence $(47.7 \%)$ of root rot ratings $\geq 30 \%$ (data not shown).

Significant differences $(P=0.05)$ among isolates and among cultivars, and were shown in the ANOVAs for severity of symptoms. For root and stem symp, the highest overall severities were most susceptible to both species (Fig. 4A moniliforme, with Grande the cultivar 
and B). In contrast, cultivars VerdeMorado, J.M. 2001, and Dariana showed the lowest root rot and stem severity values $(<50 \%)$ when inoculated with $F$. solani (Fig. 4A and B).

Significant differences $(P=0.05)$ in root and stem dry weights were detected among isolates and among cultivars, but there was no significant isolate-by-cultivar interaction. The isolates of $F$. solani, $F$. moniliforme, and $F$. proliferatum 2/4 B2 significantly reduced $(P=0.05)$ both root dry weight and stem dry weight of inoculated plants (Table 5). In addition, observed reductions in root and stem dry weights were significantly $(P=0.05)$ larger for Grande and Ciprés than those observed for Grolim, Verde-Morado, and Dariana (Table 6).

For the experiment with micropropagated plantlets, there was no significant effect of cultivars or interaction of isolates with cultivars. However, significant $(P=$ $0.05)$ differences were detected in the incidence of plants with root rot severity values $\geq 30 \%$, severity of root rot symptoms, and root dry weights among Fusarium isolates, with $F$. solani and $F$. moniliforme the most virulent of the isolates, the former causing the largest reduction in root dry weight. On the other hand, plants inoculated with $F$. proliferatum $2 / 4$ B2 also showed significant $(P=0.05)$ root dry weight reduction compared with the control, although the incidence and root rot severity values were similar to those of noninoculated plants (Table 7).

\section{DISCUSSION}

Phytopathological analysis of asparagus crowns sampled in 2002 and 2003 prior to transplanting in southern Spain showed a high incidence of plants infected by Fusarium spp. This is in agreement with results reported in other areas of the world $(4,20,40)$. The incidence of infection differed among plants sampled from various nurseries and among asparagus cultivars. The epidemiological role of infected nursery crowns is especially important when this planting material is placed in fields with no or low levels of soil inoculum, because in this case planting material constitutes the main source of inoculum.

Symptoms observed on crowns of asparagus included reddish-brown lesions on internal tissues of the rhizomes and storage roots, and necrosis in the zone of connection of secondary and main roots, and were similar to those reported elsewhere $(3,11,12,18,21,25,36)$. F . proliferatum, $F$. oxysporum, and $F$. moniliforme were the three Fusarium spp. most prevalent from the isolations of asparagus nursery crowns and were obtained mainly from the rhizomes and storage roots. Isolates of multiple Fusarium spp. were sometimes obtained from the same crown and the same piece of tissue, as observed by Durán (11), who occasionally isolated $F$. oxysporum and $F$. proliferatum from the same asparagus plant.

The frequencies of isolation of Fusarium spp. from asparagus nursery crowns and field plants, and the virulence of these

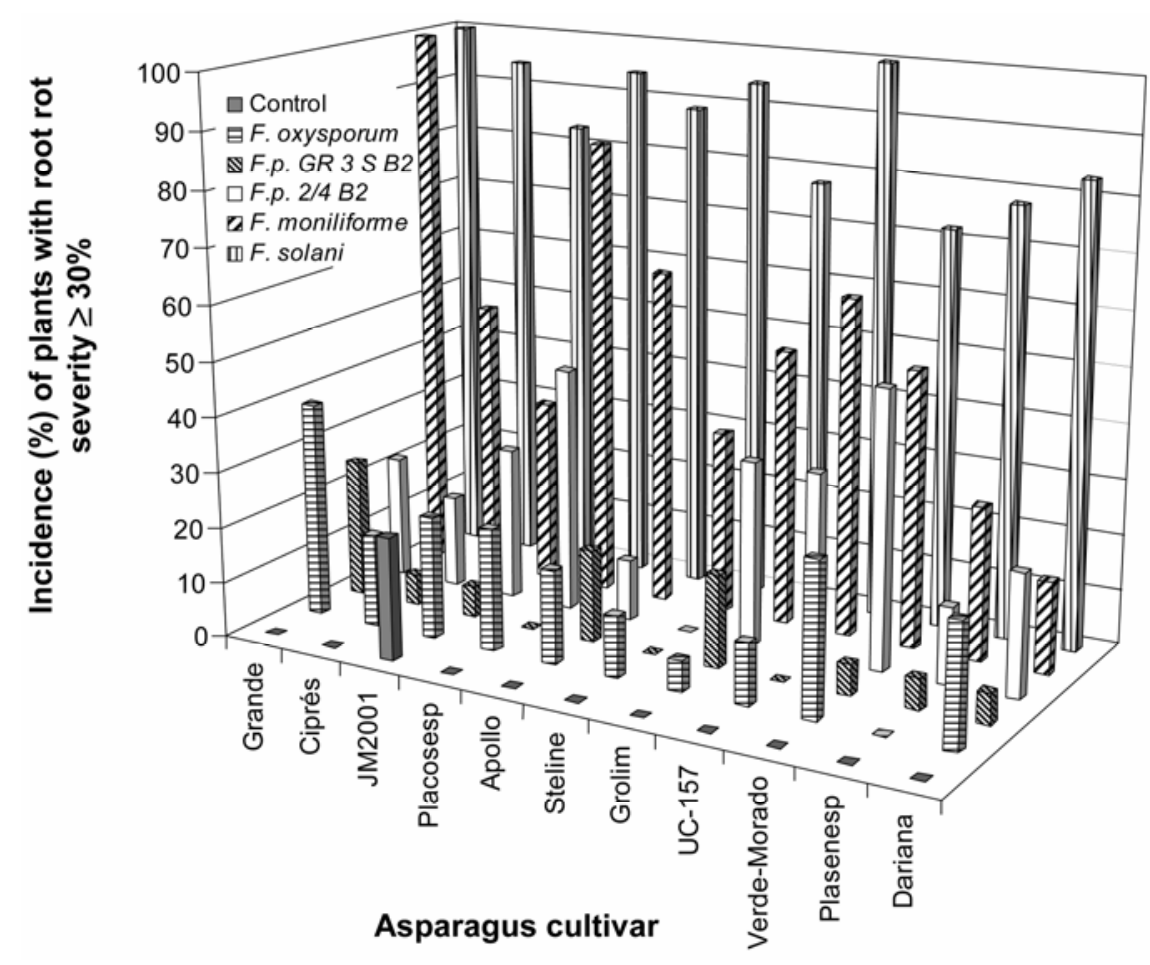

Fig. 3. Effect of different Fusarium spp. on incidence (\%) of plants with $\geq 30 \%$ of root rotted on 11 asparagus cultivars. Each data point is the mean of six pots corresponding to two replicated experiments. Standard errors for comparing two means, according to Tukey's test, are 4.17 for isolates within cultivars and 5.65 for cultivars within isolates. isolates as determined by pathogenicity tests, demonstrated that four species, i.e., $F$. proliferatum, $F$. oxysporum f. sp. asparagi, $F$. moniliforme, and $F$. solani can be considered as the most important species of Fusarium associated with the slow decline of asparagus in south Spain. This brings new insight to the complex etiology of this disease affecting asparagus planting material in south Spain, since $F$. oxysporum f. sp. asparagi had previously been reported as the only species with a high incidence in nursery crowns (11), although a minor role had also been observed for $F$. solani, $F$. moniliforme, $F$. roseum, and $F$. lateritium $(11,40)$.

The results of this study emphasize the role of $F$. solani in asparagus decline, with this species mainly isolated from rhizomes and roots of asparagus plants collected from the fields. Some F. solani isolates were extremely virulent. Similarly, these results support those from Taiwan (41) but contrast with the lack of pathogenicity or low virulence of $F$. solani isolates on asparagus demonstrated by others $(8,11,21$, 26,36). The potential importance of $F$. solani as a pathogen of asparagus was confirmed by the high virulence of the isolate inoculated onto 11 asparagus cultivars that are widely used among Spanish growers. The only exception was the autochthonous cultivar Verde-Morado, which was the least susceptible with mean root rot and stem symptom severity $<34 \%$ compared with 40 to $80 \%$ for the other cultivars evaluated.

Although the pathogenic isolates of Fusarium recovered from asparagus crowns differed in virulence following in vitro inoculations, the results were not consistent with those observed after inoculation of the monoconidial isolates onto plants grown in pots. Virulence ratings for the isolates were usually higher in the in vitro tests. This is probably attributable to the two different methods of inoculation and the type of inoculum used (bulk versus monoconidial spore suspensions). Nevertheless, for the pot experiments conducted in a growth chamber, significant differences were not found among monoconidial isolates from the same bulk isolate. Although the validity of pathogenicity tests in vitro has been discussed widely for this disease $(12,36,38)$, these results suggest that pathogenicity of the isolates should be evaluated by inoculation of plants grown in pots, which is more similar to field conditions, and in vitro evaluations are not recommended except for initial screening of isolates, when more rapid and economical evaluations are required. Isolates highly virulent on asparagus inoculated in pot tests killed inoculated plants before the end of the experiments. This would explain the lower incidence of highly virulent isolates recovered from planting material in the in vitro tests, because such highly virulent isolates may have killed plantlets in the 
nursery before the 1-year-old stage required for transplanting to commercial fields.

The similarity of symptoms on plants inoculated with different Fusarium species in the disease complex is consistent with symptoms documented in other reports $(3,7,11,12,15,18,21,26,36,40)$. Pathogenicity tests demonstrated the development of symptoms previously reported to be associated with Fusarium root and crown rot, including significant reductions in dry weight of inoculated plants, which is related to the degree of virulence of the isolates $(11,13,36)$. The loss in dry weight of asparagus plants was also observed for plants inoculated with isolates that did not cause typical root and stem symptoms. This may account for the slow decline reported in asparagus plantings in soil cropped to asparagus for the first time, as well as the significance of infected planting material as a source of inoculum for disease development.

The concurrence of morphological and RAPD analyses for the species identification of 15 of the 19 isolates of Fusarium obtained from infected asparagus crowns, i.e., eight isolates of $F$. oxysporum, four isolates of $F$. proliferatum, and three isolates of $F$. moniliforme, indicates the potential use of RAPDs as a diagnostic tool for identifying Fusarium spp. on asparagus, at least for these three species. After the amplification with primer PFE12, isolate of $F$. moniliforme $2 / 18 \mathrm{~B}$ had a banding pattern very similar to that of the four isolates of $F$. proliferatum. Dendrograms built from the amplification profiles of a large number of RAPD primers provide more accurate information on the identity of the isolates analyzed than individual interpretation of banding patterns obtained with a particular primer, which must be avoided because it can lead to misinterpretations, as in the case of $F$. moniliforme isolate 2/18 $\mathrm{B}$ amplified with primer PFE12. In this study, the coefficients of similarity for RAPD analysis within clusters I and II of 19 Fusarium isolates from asparagus were lower than $25 \%$, but the bootstrap percentages supported the stability of molecular marker-determined relationships in both clusters. Further work is needed to find RAPD bands that will discriminate $F$. oxysporum isolates pathogenic on asparagus from nonpathogenic isolates of this species. The three isolates identified as $F$. solani based on morphological observations had low similarity values in the RAPD dendrogram and did not group in the same cluster. This might be related to high genetic diversity within this species that was not identified with the RAPD primers used, and for the small number of $F$. solani isolates included in the analysis.

The results of the pathogenicity tests of asparagus cultivars to five isolates of Fusarium demonstrated that the cultivars Dariana and Verde-Morado had the lowest overall root rot and stem symptom severity values for the isolates evaluated, and Dariana had the lowest dry weight losses compared with noninoculated control plants. Combined with the agronomic qualities of these two cultivars, they appear suitable for cropping in areas with a previous history of Fusarium crown and root rot. In contrast, the widely planted cultivar Grande was the most susceptible of the 11 cultivars evaluated to the five isolates of
Fusarium tested. The selection of cultivars more resistant to Fusarium populations prevalent in asparagus cropping areas would minimize the dependency of growers on having access to pathogen-free soils for production of high-yielding asparagus crops, and would reduce asparagus crop losses.

Clonal micropropagated plantlets were less variable and less susceptible than asparagus plants produced from seeds, as
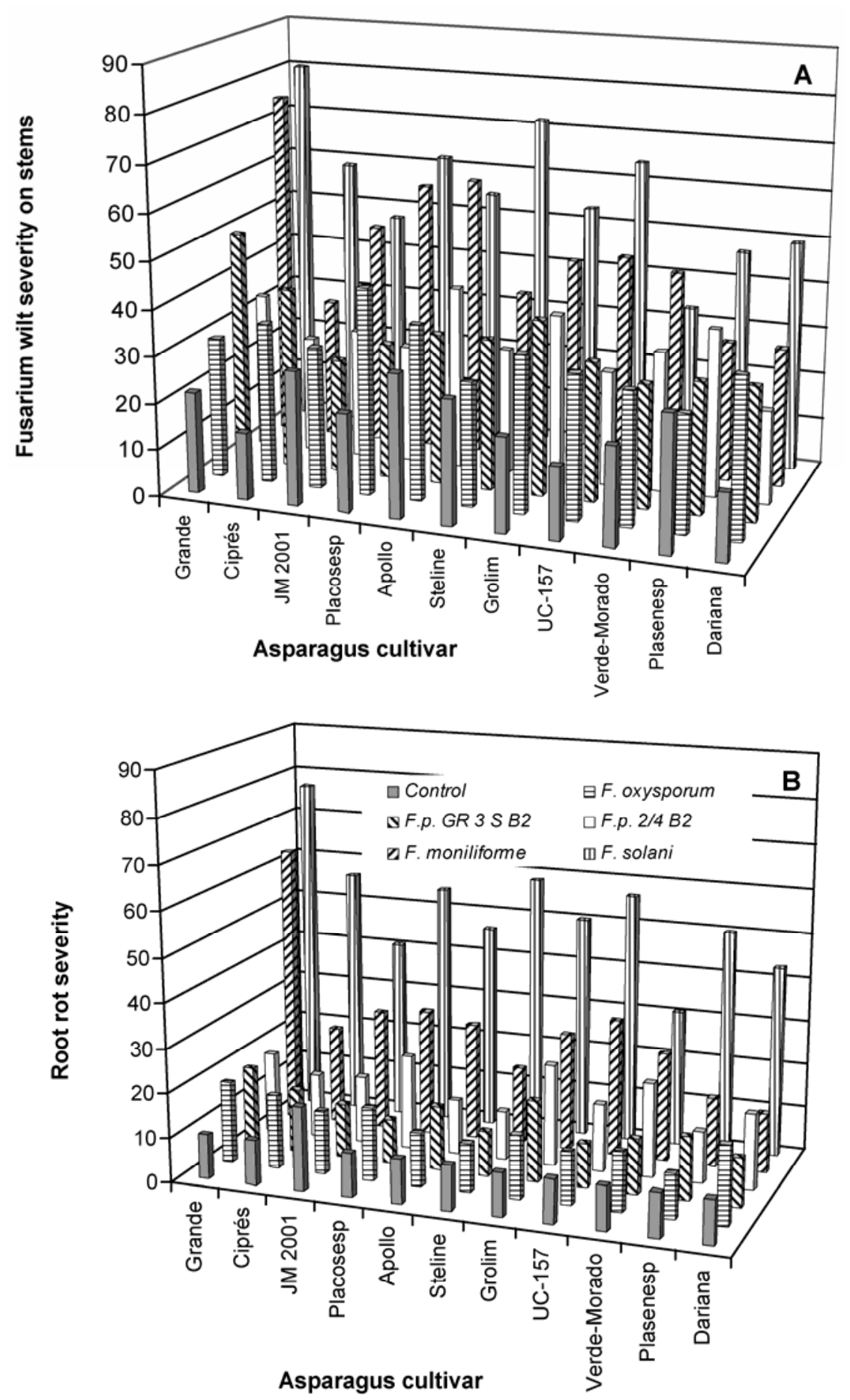

Fig. 4. Effect of different Fusarium spp. on severity of wilting of stems (A) or root rot (B) on 11 asparagus cultivars. Each data point is the mean of six pots corresponding to two replicated experiments. Standard errors for comparing two means, according to Tukey's test, are: A, for wilting of stems, 2.45 for isolates within cultivars and 3.32 for cultivars within isolates; and $\mathbf{B}$, for the severity of root rot, 1.9 and 2.58 , respectively. 
Table 5. Effect of inoculation of asparagus plants with Fusarium spp. on plant dry weights ${ }^{\mathrm{z}}$

\begin{tabular}{llc}
\hline & \multicolumn{2}{c}{ Dry weight $(\mathbf{g})$} \\
\cline { 2 - 3 } Isolate & Roots & Stem \\
\hline Control & $1.32 \mathrm{a}$ & $0.78 \mathrm{a}$ \\
F. proliferatum 2/4 B2 & $0.58 \mathrm{~d}$ & $0.56 \mathrm{~b}$ \\
$F$. proliferatum GR 3 S B2 & $1.06 \mathrm{~b}$ & $0.74 \mathrm{a}$ \\
$F$. oxysporum & $0.84 \mathrm{c}$ & $0.83 \mathrm{a}$ \\
F. moniliforme & $0.45 \mathrm{~d}$ & $0.45 \mathrm{~b}$ \\
F. solani & $0.15 \mathrm{e}$ & $0.30 \mathrm{c}$ \\
\hline
\end{tabular}

${ }^{\mathrm{z}}$ Means shown were averaged over the two experiments. Means followed by the same letter within a column are not significantly different at $P=0.05$ according to Tukey's test.

Table 6. Reaction of asparagus cultivars to inoculation with Fusarium spp. ${ }^{\mathrm{Z}}$

\begin{tabular}{lcl}
\hline & \multicolumn{2}{c}{ Dry weight $\mathbf{( g )}$} \\
\cline { 2 - 3 } Asparagus cultivar & Roots & Stem \\
\hline Dariana & $1.25 \mathrm{a}$ & $0.78 \mathrm{a}$ \\
Plasenesp & $0.91 \mathrm{~b}$ & $0.66 \mathrm{abc}$ \\
Verde-Morado & $0.85 \mathrm{bc}$ & $0.74 \mathrm{ab}$ \\
Steline & $0.64 \mathrm{bcd}$ & $0.48 \mathrm{~cd}$ \\
Apollo & $0.68 \mathrm{bcd}$ & $0.56 \mathrm{bcd}$ \\
J.M. 2001 & $0.59 \mathrm{~cd}$ & $0.60 \mathrm{abcd}$ \\
Ciprés & $0.48 \mathrm{~d}$ & $0.48 \mathrm{~d}$ \\
UC-157 & $0.82 \mathrm{bc}$ & $0.67 \mathrm{abc}$ \\
Placosesp & $0.58 \mathrm{~cd}$ & $0.55 \mathrm{bcd}$ \\
Grolim & $0.82 \mathrm{bc}$ & $0.75 \mathrm{ab}$ \\
Grande & $0.45 \mathrm{~d}$ & $0.43 \mathrm{~d}$ \\
\hline
\end{tabular}

${ }^{\mathrm{z}}$ Means shown were averaged over the two experiments. Means followed by the same letter within a column are not significantly different at $P=0.05$ according to Tukey's test.

Table 7. Incidence of root lesions in clonal micropropagated asparagus plantlets inoculated with Fusarium spp., and effect of inoculation on severity of root rot and root dry weight ${ }^{\mathrm{z}}$

\begin{tabular}{|c|c|c|c|}
\hline \multirow[b]{2}{*}{ Isolate } & \multirow{2}{*}{$\begin{array}{c}\text { Incidence }(\%) \text { of } \\
\text { plants with root rot } \\
\text { severity } \geq 30 \%\end{array}$} & \multicolumn{2}{|c|}{ Effect on roots } \\
\hline & & Root rot severity (\%) & Dry weight (g) \\
\hline Control & $3.7 \mathrm{a}$ & $10.7 \mathrm{a}$ & $1.21 \mathrm{a}$ \\
\hline F. proliferatum 2/4 B2 & $17.6 \mathrm{ab}$ & $16.8 \mathrm{ab}$ & $0.93 \mathrm{~b}$ \\
\hline F. proliferatum Gr 3 S B2 & $18.5 \mathrm{ab}$ & $14.4 \mathrm{ab}$ & $1.17 \mathrm{ab}$ \\
\hline F. oxysporum & $28.7 \mathrm{bc}$ & $16.8 \mathrm{ab}$ & $1.12 \mathrm{ab}$ \\
\hline F. moniliforme & $50.0 \mathrm{c}$ & $22.7 \mathrm{~b}$ & $0.99 \mathrm{ab}$ \\
\hline F. solani & $87.0 \mathrm{~d}$ & $50.9 \mathrm{c}$ & $0.59 \mathrm{c}$ \\
\hline
\end{tabular}

${ }^{\mathrm{z}}$ Plants were evaluated weekly for disease incidence and severity based on percentage of stem showing chlorosis or necrosis, until 3 months after inoculation. At the end of experiment, severity was assessed by percentage of roots showing symptoms of infection. Means followed by the same letter within a column are not significantly different at $P=0.05$ according to Tukey's test.

indicated by the lower reduction in root dry weight. Thus, micropropagation of asparagus might be a helpful tool for the integrated control of Fusarium crown and root rot in the nurseries, in order to maximize prevention of the disease.

\section{ACKNOWLEDGMENTS}

This work was financed by projects INIA RTA 02-216 (Ministerio de Agricultura, Pesca y Alimentación, Spain) and IFAPA/ASOCIAFRUIT CO011. The fellowship granted to C. Corpas-Hervias by IFAPA supported this work. M. L. MolineroRuiz was supported by a postdoctoral contract (I3P Program, CSIC) financed by the Social European Funds. We thank C. López-Encina (Estación Experimental La Mayora, CSIC, Málaga) for providing micropropagated asparagus plantlets, M. A. Molina, I. Teruelo, and R. del Valle (CIFA Las Torres-Tomejil, IFAPA, Sevilla) for technical assistance, and A. M. Prados for her valuable collaboration.

\section{LITERATURE CITED}

1. Baayen, R. P., Van der Boogert, P. H. J. F., Bonants, P. J. M., Poll, J. T. K., Blok, W. J., and Waalwijk, C. 2000. Fusarium redolens $\mathrm{f}$. sp. asparagi, causal agent of asparagus root rot, crown rot and spear rot. Eur. J. Plant Pathol. 106:907-912.

2. Barnett, H. L., and Hunter, B. B. 1998. Illustrated Genera of Imperfect Fungi. 4th ed. American Phytopathological Society, St. Paul, MN.

3. Blok, W. J., and Bollen, G. J. 1995. Fungi on roots and stem bases of asparagus in the Netherlands: Species and pathogenicity. Eur. J. Plant Pathol. 101:15-24.

4. Blok, W. J., and Bollen, G. J. 1996. Inoculum sources of Fusarium oxysporum f. sp. asparagi in asparagus production. Ann. Appl. Biol. 128:219-231.

5. Blok, W. J., and Bollen, G. J. 1997. Host specificity and vegetative compatibility of Dutch isolates of Fusarium oxysporum f. sp. asparagi. Can. J. Bot. 75:383-393.

6. Booth, C. 1971. The Genus Fusarium. Commonwealth Mycol. Inst., Kew, England.

7. Cohen, S. I., and Heald, F. D. 1941. A wilt and root rot of asparagus caused by Fusarium oxysporum (Schlecht.). Plant Dis. Rep. 25:503509.

8. Damicone, J. P., and Manning, W. J. 1985.
Frequency and pathogenicity of Fusarium spp. isolated from first-year asparagus grown from transplants. Plant Dis. 69:413-416.

9. Di Lenna, P., Foletto, B., and Baggio, C. 1988. Fusarium decline in asparagus. Effects of seed and soil treatments on nursery produced crowns. HortScience 2:43-47.

10. Doan, M. C., and Carris, L. M. 1998. Characterization of Fusarium oxysporum populations associated with asparagus nurseries in Washington. (Abstr.) Phytopathology 88:S22.

11. Durán, R. M. 2001. Etiología de enfermedades de espárrago causadas por patógenos de suelo en Andalucía. Ph.D. thesis. University of Córdoba, Spain.

12. Elena, K., and Kranias, L. 1996. Fusarium spp. as a cause of crown and root rot of asparagus in Greece. Bull. OEPP/EPPO 26:407411.

13. Elmer, W. H. 1990. Fusarium proliferatum as a causal agent in Fusarium crown and root rot of asparagus. Plant Dis. 74:938.

14. Elmer, W. H. 1991. Vegetative compatibility groups of Fusarium proliferatum from asparagus and comparisons of virulence, growth rates, and colonization of asparagus residues among groups. Phytopathology 81:852-857.

15. Elmer, W. H. 2001. Fusarium diseases of asparagus. Pages 248-262 in: Fusarium. Paul E. Nelson Memorial Symposium. B. A. Summerell, J. F. Leslie, D. Backhouse, W. L. Bryden, and L. W. Burgess, eds. American Phytopathological Society, St. Paul, MN.

16. Elmer, W. H., Johnson, D. A., and Mink, G. I. 1996. Epidemiology and management of the diseases causal to asparagus decline. Plant Dis. 80:117-125.

17. Elmer, W. H., and Stephens, C. T. 1989. Classification of Fusarium oxysporum f. sp. asparagi into vegetatively compatible groups. Phytopathology 79:88-93.

18. Endo, R. M., and Burkholder, E. C. 1971. The association of Fusarium moniliforme with the crown complex of asparagus. Phytopathology 61:891.

19. Esparza, M. 1988. Problemática de las plagas y enfermedades del espárrago. Phytoma España 0:27-40.

20. Fantino, M. G., and Fantuz, F. 1990. The sanitary state of asparagus nurseries in EmiliaRomagna in 1988-1989. Acta Hortic. 271:120125.

21. Gindrat, D., Varady, C., and Neury, G. 1984 Le dépérissement d'asperge. Rev. Suisse Vitic. Arboric. Hortic. 16:23-26.

22. Guerrero, C., Nigh, E. L., Jr., and Stanghellini, M. E. 1999. Incidence of Fusarium spp. in asparagus fields in Mexico and southern California. Acta Hortic. 479:231-235.

23. Inglis, D. A. 1980. Contamination of asparagus seed by Fusarium oxysporum f. sp. asparagi and Fusarium moniliforme. Plant Dis. 64:7476.

24. Jaccard, P. 1908. Nouvelles recherches sur la distribution florale. Bull. Société Vaudoise Sci. Naturelles 44:223-270.

25. Johnston, S. A., Springer, J. K., and Lewis, G. D. 1979. Fusarium moniliforme as a cause of stem and crown rot of asparagus and its association with asparagus decline. Phytopathology 69:778-780.

26. LaMondia, J. A., and Elmer, W. H. 1989 Pathogenicity and vegetative compatibility among isolates of Fusarium oxysporum and $F$. moniliforme colonizing asparagus. Can. J. Bot. 67:2420-2424.

27. Lassaga, S. L., Camadro, A. L., and Babinec, F. J. 1998. Assessing genetic variability for Fusarium resistance in three asparagus populations with an in vitro assay. Euphytica 103:131-136.

28. Lori, G., Wolcan, S., and Mónaco, C. 1998. Fusarium moniliforme and $F$. proliferatum isolated from crown and root rot of asparagus and 
their association with asparagus decline in Argentina. Plant Dis. 82:1405.

29. Mace, M. E., Bell, A. A., and Beckman, C. H. 1981. Fungal Wilt Diseases of Plants. Academic Press, Inc., New York.

30. McIntosh, M. S. 1983. Analysis of combined experiments. Agron. J. 75:153-155.

31. Melo, I. S., Faull, J. L., and Graeme-Cook, K. A. 1997. Relationship between in vitro cellulase production of UV-induced mutants of Trichoderma harzianum and their bean rhizosphere competence. Mycol. Res. 101:1389-1392.

32. Nei, M., and Kumar, S. 2000. Accuracies and Statistical Tests of Phylogenetic Trees. Pages 165-186 in: Molecular Evolution and Phylogenetics. Oxford University Press, NY

33. Nelson, P. E., Toussoun, T. A., and Marasas, W. F. O. 1983. Fusarium species: An Illustrated Manual for Identification. Pennsylvania State University, University Park.
34. Nyvall, R., and Kommedahl, T. 1968. Individual thickened hyphae as survival structures of Fusarium moniliforme in corn. Phytopathology 58:1704-1707.

35. Raeder, U., and Broda, P. 1985. Rapid preparation of DNA from filamentous fungi. Lett. Appl. Microbiol. 1:17-20.

36. Schreuder, W., Lamprecht, S. C., Marasas, W. F. O., and Calitz, F. J. 1995. Pathogenicity of three Fusarium species associated with asparagus decline in South Africa. Plant Dis. 79:177-181.

37. Serrano, Z. 2003. Espárrago: Técnicas de producción. Z. Serrano Cermeño, ed. Impresos Izquierdo, S. A., Madrid, Spain.

38. Stephens, C. T., and Elmer, W. H. 1988. An in vitro assay to evaluate sources of resistance in Asparagus spp. to Fusarium crown and root rot. Plant Dis. 72:334-337.

39. Summerell, B. A., Salleh, B., and Leslie, J. F. 2003. A utilitarian approach to Fusarium iden- tification. Plant Dis. 87:117-128.

40. Tello, J. C., González, M. L., and Lacasa, A. 1985. The "Fusariosis" (disease produced by Fusarium spp.) of asparagus in Spain. Pages 126-135 in: Proc. 6th Int. Asparagus Sympos. E. C. Loungheed and H. Tiessen, eds. University of Guelph, Ontario, Canada.

41. Tu, C. C. 1980. Studies on fusarial wilt and root disease complexes of asparagus in Taiwán. Pages 180-186 in: Proc. 5th Int. Asparagus Sympos. G. Reuther, ed. Wageningen, The Netherlands.

42. Tuite, J. 1969. Plant Pathological Methods: Fungi and Bacteria. Burgess Publishing Company, Minneapolis, MN.

43. Voigt, K., Schleier, S., and Bruckner, B. 1995. Genetic-variability in Gibberella fuji kuroi and some related species of the genus Fusarium based on Random Amplification of Polymorphic DNA (RAPD). Curr. Genet. 27:528-535. 